\title{
Six3 demarcates the anterior-most developing brain region in bilaterian animals
}

\author{
Patrick RH Steinmetz ${ }^{1,6 \dagger}{ }^{1}$, Rolf Urbach ${ }^{2 \dagger}$, Nico Posnien ${ }^{3,7}$, Joakim Eriksson ${ }^{4,8}$, Roman P Kostyuchenko ${ }^{5}$, Carlo Brena ${ }^{4}$,
} Keren Guy ${ }^{1}$, Michael Akam ${ }^{4^{*}}$, Gregor Bucher ${ }^{3 *}$, Detlev Arendt ${ }^{{ }^{*}}$

\begin{abstract}
Background: The heads of annelids (earthworms, polychaetes, and others) and arthropods (insects, myriapods, spiders, and others) and the arthropod-related onychophorans (velvet worms) show similar brain architecture and for this reason have long been considered homologous. However, this view is challenged by the 'new phylogeny' placing arthropods and annelids into distinct superphyla, Ecdysozoa and Lophotrochozoa, together with many other phyla lacking elaborate heads or brains. To compare the organisation of annelid and arthropod heads and brains at the molecular level, we investigated head regionalisation genes in various groups. Regionalisation genes subdivide developing animals into molecular regions and can be used to align head regions between remote animal phyla.

Results: We find that in the marine annelid Platynereis dumerilii, expression of the homeobox gene six 3 defines the apical region of the larval body, peripherally overlapping the equatorial otx + expression. The six $3+$ and ot $x+$ regions thus define the developing head in anterior-to-posterior sequence. In another annelid, the earthworm Pristina, as well as in the onychophoran Euperipatoides, the centipede Strigamia and the insects Tribolium and Drosophila, a six3/optix+ region likewise demarcates the tip of the developing animal, followed by a more posterior otx/otd+ region. Identification of six3+ head neuroectoderm in Drosophila reveals that this region gives rise to median neurosecretory brain parts, as is also the case in annelids. In insects, onychophorans and Platynereis, the otx + region instead harbours the eye anlagen, which thus occupy a more posterior position.

Conclusions: These observations indicate that the annelid, onychophoran and arthropod head develops from a conserved anterior-posterior sequence of six $3+$ and otx + regions. The six $3+$ anterior pole of the arthropod head and brain accordingly lies in an anterior-median embryonic region and, in consequence, the optic lobes do not represent the tip of the neuraxis. These results support the hypothesis that the last common ancestor of annelids and arthropods already possessed neurosecretory centres in the most anterior region of the brain. In light of its broad evolutionary conservation in protostomes and, as previously shown, in deuterostomes, the six3-otx head patterning system may be universal to bilaterian animals.
\end{abstract}

\section{Background}

The brains of annelids and arthropods are similarly composed of cerebral ganglia located above the foregut and a variable number of associated segmental ganglia,

\footnotetext{
* Correspondence: m.akam@zoo.cam.ac.uk; gregor.bucher@bio.unigoettingen.de; detlev.arendt@embl.de

+ Contributed equally

'Developmental Biology Unit, European Molecular Biology Laboratory, Meyerhofstrasse 1, 69012 Heidelberg, Germany

${ }^{3}$ Johann-Friedrich-Blumenbach-Institute of Zoology, Anthropology and Developmental Biology, DFG Research Centre for Molecular Physiology of the Brain (CMPB), Georg August University, von-Liebig-Weg-11, 37077

Göttingen, Germany

Full list of author information is available at the end of the article
}

incorporated to the brain through cephalisation $[1,2]$. In annelids, the cerebral ganglia develop, at least in their largest part, from the neuroectoderm of the prostomium, the most anterior part of the annelid body. In polychaete annelids with indirect development, the prostomium forms from the larval episphere, the upper half of the trochophora larva (the apical "cap" anterior to the primary trochoblasts forming the prototroch ciliary ring) (Figure 1b). A smaller subset of cerebral neurons forms from the peristomium, the more posterior part of the developing head that contains the mouth and lies anterior to the first metameric segment. The peristomium forms from the equatorial larval regions including the

\section{Biomed Central}




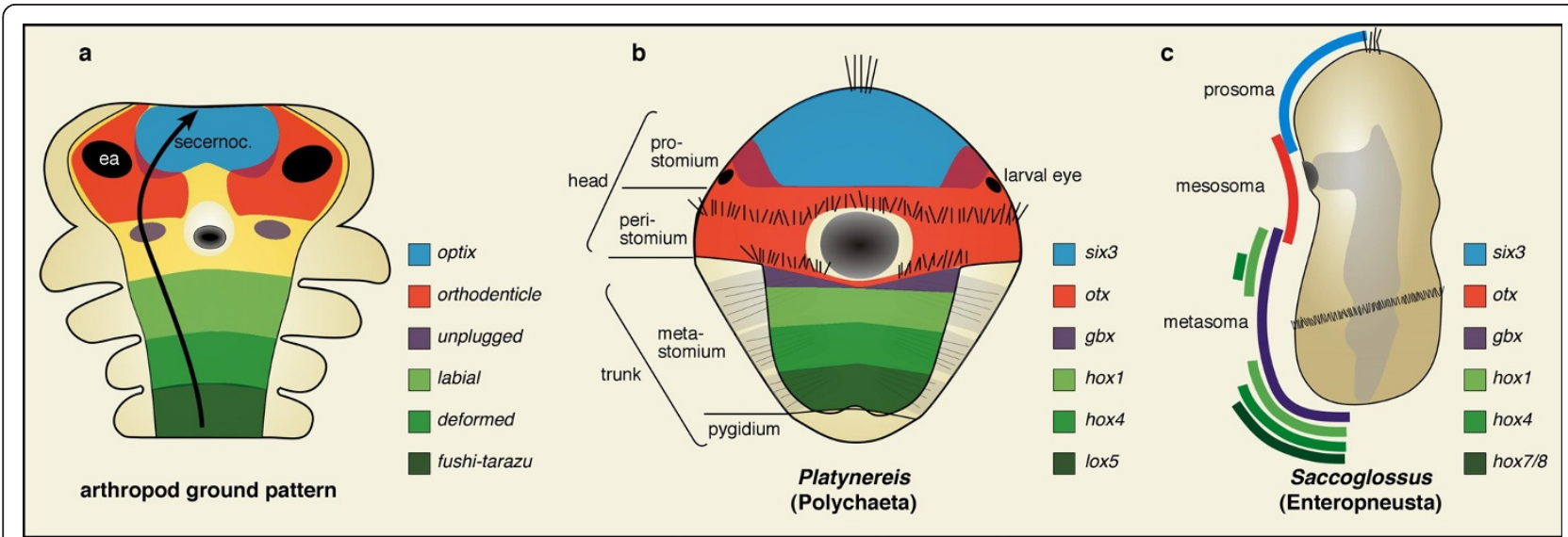

Figure 1 Conservation of anterior-posterior six3/optix-, gbx/unplugged and Hox-expressing territories in Bilateria. A conserved anteriorposterior alignment of six3/optix-, otx/otd-, gbx/unplugged- and hox-expressing neuroectodermal regions in the hypothetical ancestral arthropod (a), the annelid Platynereis (b), and the hemichordate Saccoglossus (c). (a) Arrow depicts the antero-posterior neuraxis pointing at the anteriormost six3/optix-region as identified by the data presented here. Light grey in (b): developing parapodial appendages, in (c): gut. Dark grey: mouth opening. Yellow: neuroectoderm not expressing any of the mentioned genes. Purple in $(a, b)$ : six $3+/ o t x+$ regions. All animals are oriented with anterior to the top. (a, b): ventral views. (c): lateral view. ea: eye anlage. Arthropod schematic after [29,36-38,48-53], Platynereis and Saccoglossus schematics after references in the text.

larval foregut (stomodaeum), the prototroch and metatroch ciliary bands if present (Figure 1b) [3,4].

In arthropods, the cerebral ganglia are composed of the protocerebrum and two segmental neuromeres, the deuto- and tritocerebrum. The most anterior part, the protocerebrum, can be further subdivided into a more lateral region bearing, for example, the optic lobes (archicerebrum) and a median region that includes, for example, the pars intercerebralis (prosocerebrum). Most authors think that the archicerebrum represents the tip of the neuraxis [1,5-8] but this has been disputed [9-11]. So far, it is unclear how the arthropod and annelid brain parts are related, if at all, and how they would align along the anterior-posterior axis $[7,8,12,13]$. In order to molecularly reassess this long-standing question, we have compared the expression of the anterior regionalisation genes six 3 and otx during the development of annelid, arthropod and onychophoran brains.

\section{Results and discussion}

To elucidate head regionalisation in annelids (Figure 1b), we screened candidate genes for broad regional expression in the larval episphere and, at later developmental stages, in the prostomium. Previous studies identified molecular markers for sub-regions of the episphere and prostomium (for example, $P d u-r x, P d u-n k 2.1, P d u-p a x 6$ ) [14], for the equatorial ciliary girdle and mouth region giving rise to the non-metameric peristomium ( $P d u$-otx) $[15,16]$, and for the posteriorly adjacent larval segment giving rise to the segmented trunk neuroectoderm ( $g b x$ [15] and hox [17]; Figure 1b). In order to identify a broad regionalisation marker for the anterior-most prostomium, we tested six3, because in vertebrates the spatially restricted expression of this gene demarcates the most anterior neural plate region [18] and is required for the formation of anterior structures [19]. six 3 also demarcates the anterior body section of the enteropneust Saccoglossus [20] (Figure 1c) and of the sea urchin Strongylocentrotus purpuratus larvae [21], consistent with a conserved role in the specification of the front end of the body. In the marine annelid Platynereis dumerilii (Polychaeta, Phyllodocida), Pdu-six3 (Additional file 1: Supplementary Figure 1a) indeed proved to be a specific marker for almost the entire episphere, expressed at early (Figure 2a, c, d) and late larval stages (Figure 2e and Additional file 1: Supplementary Figure 2a, c). None of more than 100 other transcription factors tested showed a similarly broad and contiguous episphere-specific expression ([22] and data not shown). The broad apical domain of $P d u$-six 3 expression (Figure $2 \mathrm{a}, \mathrm{c}, \mathrm{d}$ ) includes the anlagen of the antennae and palpae and is surrounded by the ring-like peristomial expression of Pdu-otx [16] (Figure 2b-d, Additional file 1: Supplementary Figure 2b, 1), which covers equatorial/ peristomial larval regions and overlaps with six 3 in the periphery of the episphere (Figure $2 \mathrm{~d}-\mathrm{f}$ ). The developing prostomium thus includes six3+ and six3+/otx + coexpressing parts, while the peristomium expresses ot $x$ only (Figure 1b). Both six $3+$ and $o t x+$ cells include neural progenitors and differentiating neurons as evidenced by co-expression with differentiation markers at $48 \mathrm{hpf}$ (data not shown). As the positions of the mouth 


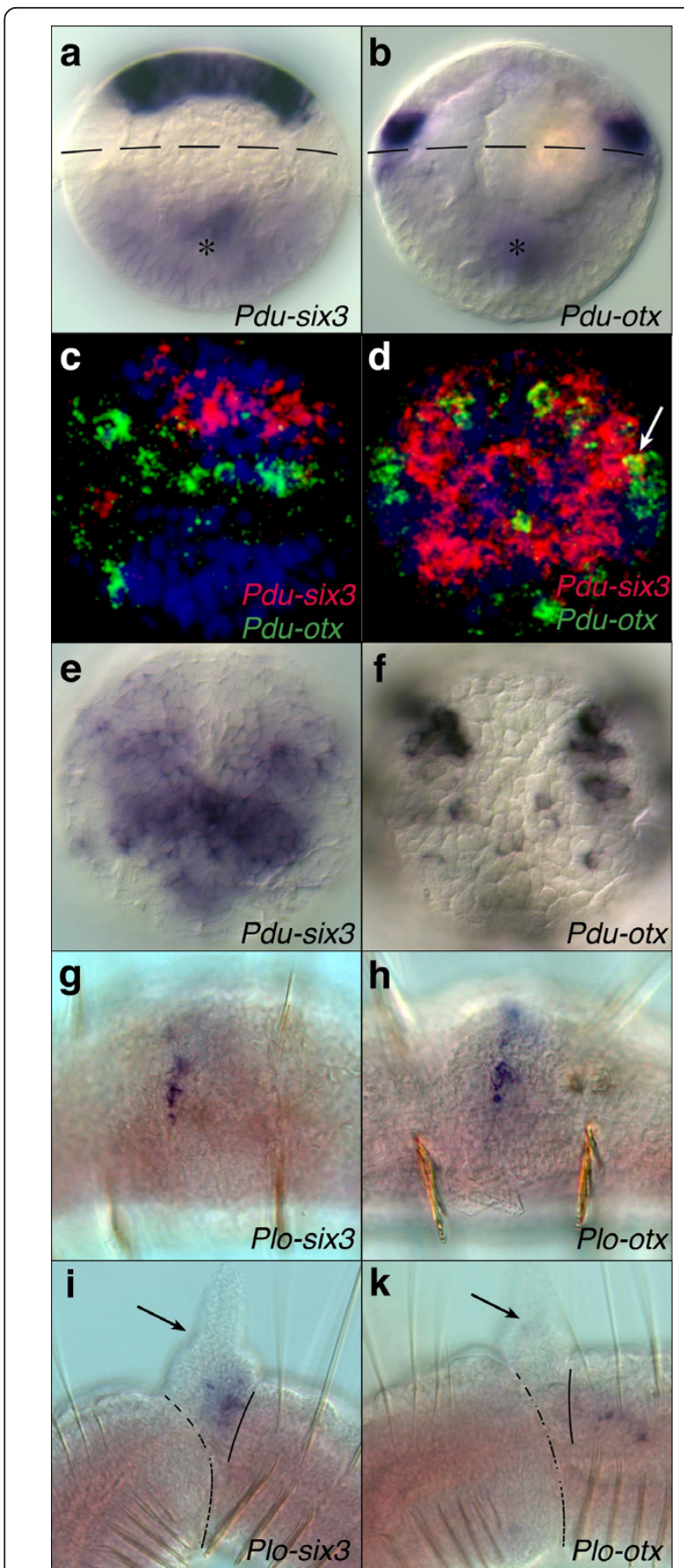

Figure 2 Expression of annelid otx and six 3 genes. In the polychaete annelids Platynereis (a-f) and Pristina $(g-k)$, six3 orthologues (a, c-e, g, i) are expressed anterior of otx orthologues $(b-d, f, h, k)$. Single $(a, b, e-k)$ or two-colour (c, d) whole-mount in situ hybridisations. Twenty-four hours $(a-d)$ or $48 \mathrm{~h}(e, f)$ old Platynereis larvae. Pristina early $(\mathrm{g}, \mathrm{h})$ and late (i, k) fission stage. Asterisks in ( $a, b)$ point out stomodaeal expression (out of focus). Dashed line: Prototroch ciliary band. (c,d) Blue: nuclear DAPI stain. (i, k) Dotted line: Boundary of two forming worms dividing by fission; continuous line: Plo-six3/Plo-otx expression boundary. Arrows: Tentacles protruding dorsally from the anterior tip of the forming worm. and eyes have often been used as landmarks to align the annelid and arthropod body regions, we also tried to affiliate the origin of these structures to the six3+ or ot $x+$ regions. In Platynereis, Pdu-six3 is expressed in the stomodaeal roof (Additional file 1: Supplemental Figure 2 a, c), while the stomodaeal Pdu-otx expression starts broadly and becomes more restricted to single cells during later stages (Additional file 1: Supplementary Figure $2 \mathrm{~b}, \mathrm{~d})$. Thus, the stomodaeum is of mixed quality, but has its opening clearly surrounded by the ot $x+$ peristomial region (Additional file 1: Supplementary Figure 2a, b, yellow arrowheads). At $24 \mathrm{hpf}$, the Pdu-tryptophane2,3-dioxygenase-expressing rhabdomeric larval eyes express Pdu-otx (Additional file 1: Supplementary Figure 2l) but not Pdu-six3 (not shown). While the early $P d u$-six3+ region is almost devoid of $P d u$-otx expression, both genes overlap more broadly at later larval stages (Figure 2a-d, Additional file 1: Supplementary Figure 2c, d and data not shown) in brain regions that include the Pdu-r-opsin + adult eyes [23] (Additional file 1: Supplementary Figure $21, \mathrm{~m}$ and data not shown). Thus, otx expression is shared by all eyes in Platynereis (as it is in Drosophila), while only a subset expresses additional six3, for example the Platynereis adult eyes (similar to the Drosophila compound eyes that express and require six3/optix [24]).

To obtain independent evidence that six3 plays a conserved role in outlining the most anterior head region in annelids, we cloned and investigated the expression of otx and six3 orthologs (Additional file 1: Supplementary Figure 1) in the oligochaete annelid Pristina longiseta that asexually reproduces by fission into chains of individuals that each regenerate a full anterior-posterior axis [25]. During early fission, both genes are expressed in stripes at the putative anterior part of the newly forming head in the middle of a segment (Figure $2 \mathrm{~g}, \mathrm{~h}$ ). At this stage, we were technically not able to resolve whether Plo-six3 lies anterior of Plo-otx. However, in later stages, using the developing antennae for spatial reference, we indeed observed a single patch of Plo-six3 expressing cells at the tip of a newly forming individual (Figure 2i), in front of otx expressing cells [26] (Figure 2k).

We next tested whether a similar sequence of six3+ and ot $x+$ regions also hallmarks the anterior end of the arthropod body (Figure 3). In the fly Drosophila, we found that optix/six3 indeed lies anterior of, and partly overlaps with, orthodenticle/otx expression at stage 6 (late blastoderm) and stage 11 (elongated germ band) (Figure 3a-c). However, since anterior-posterior patterning in Drosophila is known as being evolutionarily modified, we studied the beetle Tribolium castaneum where an otx gene ortholog forms part of a more ancestral anterior patterning system [27]. The expression of Tcsix3 (Additional file 1: Supplementary Figure 1a) 


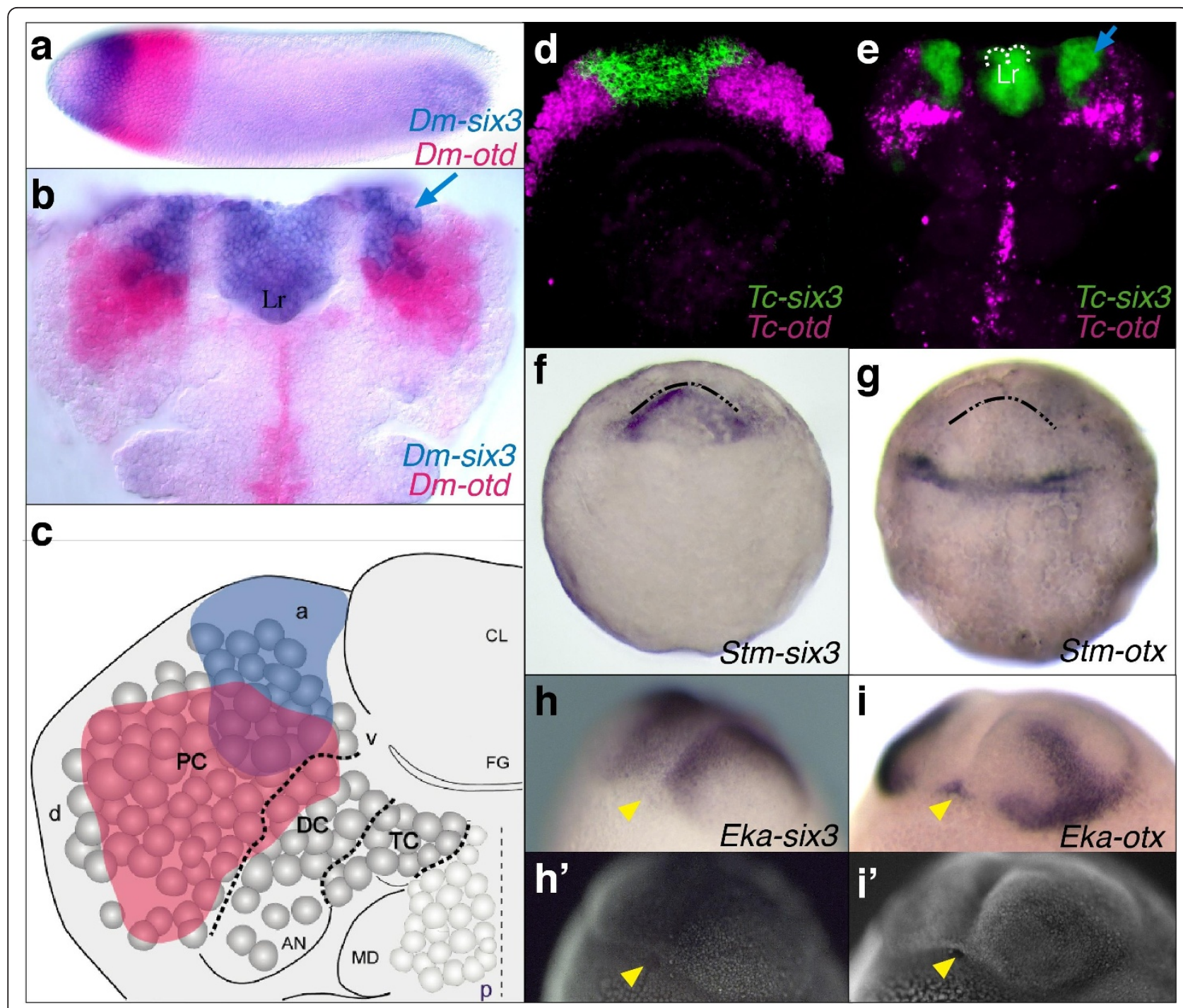

Figure 3 Expression of insect, centipede and onychophoran six 3 and otx genes. In the fly Drosophila (a-c), the beetle Tribolium (d, e), the centipede Strigamia $(f, g)$, the onychophoran Euperipatoides ( $\left.h-i^{\prime}\right)$, six3/optix orthologues $(a-f, h)$ are expressed in an anterior-median location, while otx/orthodenticle orthologues (a-e, g, i) are expressed more posterior-laterally. Single (f-i') or two-colour (a, b, d, e) whole-mount in situ hybridisations. (a, b) Drosophila stage 6 (a) and 11 (b). (c) Schematics of six3 (blue) and otx (red) neuroectodermal expression in the left head hemisphere of a stage 11 Drosophila; expression of both genes is also detected in the underlying brain neuroblasts [36]. (d, e) Tribolium germ rudiment (d) and early elongating germband (e) stages. (f, g) Strigamia early segmentation stages. (h-i') Euperipatoides mid-segmentation stages. $\left(h^{\prime}, i^{\prime}\right)$ : nuclear SYBRGreen stain of embryos in ( $h$, i) for better visualization of the mouth opening. Dotted line in (e): Anterior labral border. Blue arrows in (b, e): six3+ neuroblasts. Dashed/dotted lines in ( $f, g)$ : anterior germband margin. Yellow arrowheads in ( $\left.h-i^{\prime}\right)$ : mouth opening. Abbreviations: $\mathrm{a}=$ anterior, $\mathrm{AN}=$ antennal segment, $\mathrm{CL}=$ clypeolabrum, $\mathrm{d}=$ dorsal, $\mathrm{DC}=$ deutocerebrum, $\mathrm{FG}=$ foregut, $\mathrm{Lr}=\mathrm{labrum}, \mathrm{MD}=$ mandibular segment, $\mathrm{p}=$ posterior, $\mathrm{PC}=$ protocerebrum, $\mathrm{TC}=$ tritocerebrum, $\mathrm{v}=$ ventral. Thin dashed line in (c): midline; thick dotted lines in (c): posterior borders of the protocerebrum, deuterocerebrum and tritocerebrum. (a): Lateral view. (b-g): Ventral views. (h-i'): Ventro-lateral views. All embryos with anterior to top except a: anterior to left.

demarcates a region at the tip of the germ rudiment [28], anteriorly adjacent to the expression region of $T c$ otd1 (Figure 3d), which is the only beetle otx paralog expressed at early stages [29]. At the elongated germband stage, the Tc-six3 (Figure 3e) and Drosophila six3 (Figure 3b, c) expression regions are very similar and remain located at the anterior-median edge of the germband, including the labrum (Figure 3b, e), anterior brain neuroectoderm (Figure 3b, e) and corresponding neuroblasts (Figure 3c) [28] and is later also found in the developing stomodaeal roof (not shown). This result suggests that the role of six 3 as a regional specification gene for the formation of the most anterior head and brain region, as shown in Drosophila and vertebrates, is 
conserved throughout Bilateria $[19,30]$. To validate evolutionary conservation of the anterior six 3 region in other panarthropods, we isolated the six 3 and otx orthologues (Additional file 1: Supplementary Figure 1) from the centipede Strigamia maritima (Stm-six3, Stm-otx) and from the velvet worm Euperipatoides kanangrensis (Eka-six3, Eka-otx) and for both species found six 3 expressed in an anterior-median region at the tip of the germband and at later stages (Figure 3f, $\mathrm{h}$ and Additional file 1: Supplementary Figure 2e, g, i), while otx is mostly confined to more posterior and lateral coordinates (Figure 3g,i and Additional file 1: Supplementary Figure 2f, h, k). In Euperipatoides, the Eka-six3 domain includes the antennal anlagen, while the eye anlagen, as in other panarthropods, lie within the more lateral $E k a-o t x+$ domain (Figure 3h-i', Additional file 1: Supplementary Figure 2i, k) [31,32]. As in Platynereis and Drosophila (Figure $3 \mathrm{~b}$ ), the mouth opening lies within a ventral patch of otx expressing cells (Figure 3i, i', yellow arrowheads). At late Strigamia stages, the mouth opening is broadly surrounded by six 3 expression, but also expresses otx at the posterior border (Additional file 1: Supplementary Figure $2 \mathrm{~g}, \mathrm{~h}$ ). For Euperipatoides and Strigamia, the embryonic origin of the cells giving rise to the mouth is unclear.

What is the fate of the six $3+$ region in the diverse groups? In vertebrates, one prominent site of six 3 activity is the developing hypothalamus $[18,33]$. Since in Platynereis, Pdu-six3 expression broadly covers the medial brain anlagen, it includes a large part of the early differentiating neurosecretory cells recently identified in the 48 hpf Platynereis brain anlage [14] (Additional file 1: Supplementary Figure 2c and data not shown). In insects, the neurosecretory pars intercerebralis and pars lateralis also originate from an anteriormedian head position suggesting their origin from a six3-expressing region $[34,35]$. To validate this, we mapped six3/optix expression in the Drosophila head ectoderm and in brain neuroblasts (Figure 3b, c and Figure 4) [36]. We indeed found that the Six3+ dorsal brain region includes the developing Dchx $1+$ pars intercerebralis (Figure 4a-a", d) and the Fas2+ pars lateralis (Figure 4b-b", d), both also positive for the invaginating placode marker Crumbs (Figure 4c, c', d) [35]. Thus, the anlagen for the neurosecretory pars intercerebralis and pars lateralis lie within the six3+ region (Figure 3).

\section{Conclusions}

Our comparative expression data shows that the developing annelid, arthropod and onychophoran heads comprise an anterior-most six $3+$ region and a more posterior otx + region. Both regions are overlapping to a variable degree but show a clear anterior-to-posterior sequence, allowing cross-phylum alignment of head regions. In arthropods, the six $3+$ and $o t x+$ head regions give rise to the protocerebrum and to the eyes (Figure 1a). In annelids, the six 3 +and otx+ regions cover the developing prostomium and the peristomium, from which the cerebral ganglia and eyes (and chemosensory appendages) develop (Figure 1b), but the six3/otx-based molecular subdivision does not fully match the morphological partition. While neuroectodermal six3 is restricted to the larval episphere and thus to the prostomium, the more posterior/equatorial otx expression covers the peristomium but also part of the prostomium where it overlaps with six 3 . Our data thus align annelid cerebral ganglia with arthropod protocerebrum (that is, the most anterior part of the arthropod cerebral ganglia, see "Background").

Many authors have argued that the most anterior structures in the arthropod brain are the anterior-lateral regions mainly consisting of the optic lobe [1,5-8]. These ocular regions largely coincide with the otx + region (Figure 1a). Yet, the clear anterior location of the six $3+$ region in the early embryos of diverse arthropods, together with the role of six 3 in defining the most anterior structures in other phyla, strongly suggest that it is this median six $3+$ region, giving rise to the neurosecretory pars intercerebralis and pars lateralis that represents the most anterior extreme of the arthropod brain (arrow in Figure 1a) and corresponds to the neurosecretory brain parts in annelids. This has hitherto been a minority view [9-11]. As the terms "archicerebrum" and "prosocerebrum" are tightly connected with the Articulata theory - unsupported by almost all molecular phylogenies - and have been inconsistently used to include different brain regions, we suggest abandoning these terms. Instead, our comparative studies reveal the existence of a conserved, ancient neurosecretory brain part at the tip of the neuraxis (Figure 1). It is followed by a more posterior part of the head (and brain) anlage expressing otx that often exhibits an early ring or arclike pattern $[29,37,38]$, consistent with the radial head hypothesis [39], and includes the eye anlagen (Figure 1). In the animals investigated, the position of the mouth opening is not reliably connected to the $\operatorname{six} 3$ or otx region: while it comes to lie within the otx region of Platynereis and onychophorans, its origin in arthropods is unclear. The fact that the annelid and onychophoran antennae develop from the six $3+$ region, in contrast to the arthropod antennae that develop posterior to the otx + protocerebrum, is consistent with the previous assumption of homology between annelid and onychophoran antennae, but not with arthropod antennae [13]. The striking overall evolutionary conservation of a six3+ region in front of $o t x+$ and hox + regions in protostomes documented here (Figure 1), as well as in vertebrates 


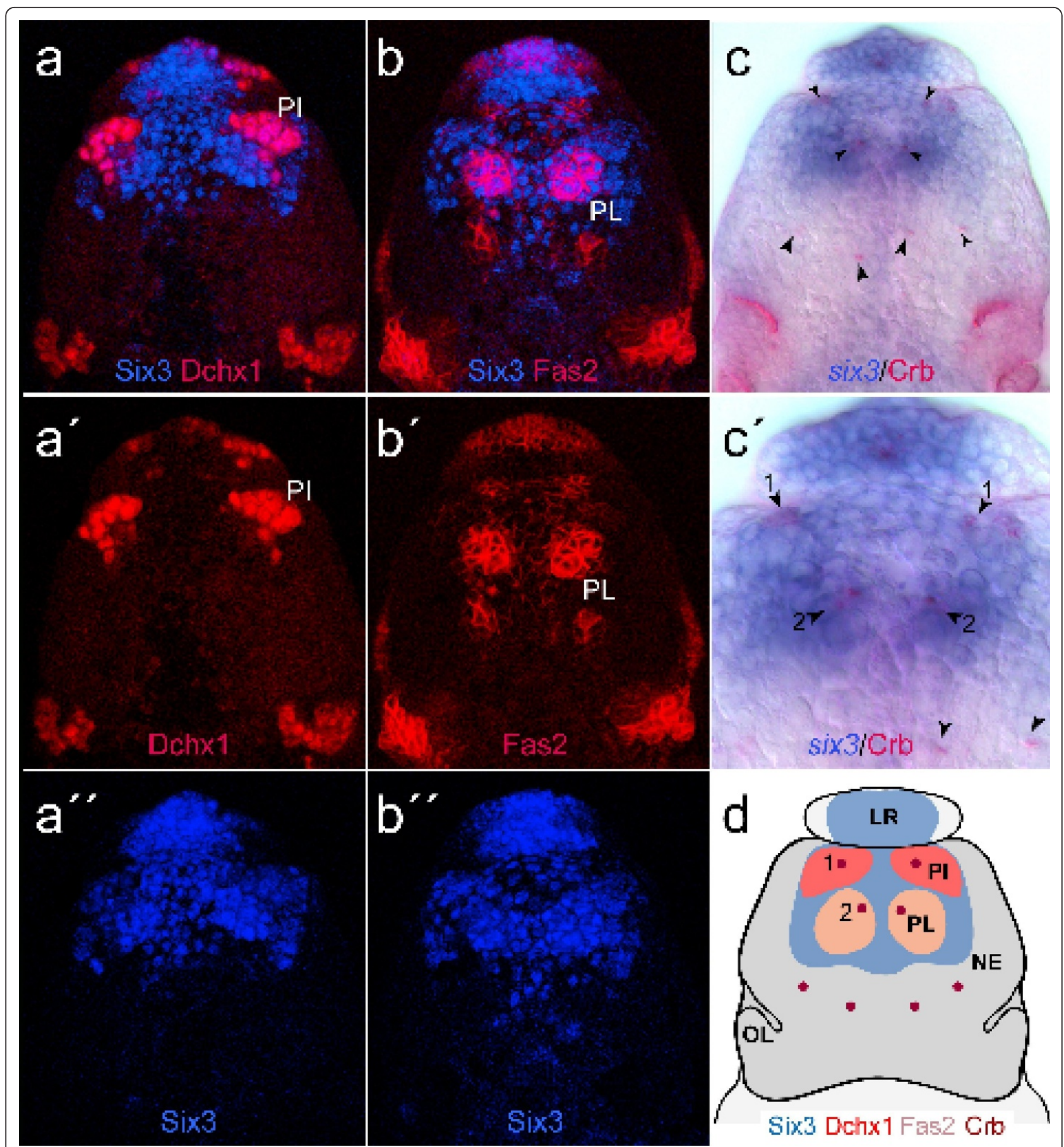

Figure 4 The Drosophila six3/optix-expressing region includes neurosecretory centres. The neuroectodermal domains of the Drosophila neurosecretory pars intercerebralis (PI) and pars lateralis (PL) lie within the six3/optix-expressing region. (a, $\left.a^{\prime}, a^{\prime \prime}\right)$ Six3/Dchx1 protein expression. $\mathrm{Six} 3$ is detected in the neuroectoderm of the developing PI, as is specifically indicated by the expression of Dch $\times 1$. ( $\left(b_{1}, b^{\prime}, b^{\prime \prime}\right)$ Six3/Fas2 protein expression. Six3 is additionally found to be expressed in the neuroectodermal placode of the developing PL, as is indicated by the strong expression of Fas2 [35]. (c, c') six3 mRNA/Crumbs protein expression. (c') Higher magnification of the six3-expressing head region. Black arrowheads in (c') depict invaginating placodal cells of the PI (1) and PL (2) as visualized by apically concentrated localisation of the Crumbs protein [35]; as is indicated by the red dots in (d). (d) Schematic summary of the expression of Six3, Dchx1, Fas2, and Crumbs in the anteriordorsal head ectoderm, including the neuroectodermal placodes of the PI and PL, as is depicted by the colour code. $L R=$ labrum; $N E=$ neuroectoderm; $\mathrm{OL}=$ optic lobe anlagen; $\mathrm{PI}=$ pars intercerebralis; $\mathrm{PL}=$ pars lateralis. 
and hemichordates, indicates that this anterior-posterior series may be universal to bilaterian animals.

\section{Methods}

Animal culture and collecting

Platynereis larvae obtained from an established breeding culture at EMBL, Heidelberg. Strigamia maritima eggs collected at Brora, Scotland (June 2006). Fly strains: Oregon R (wildtype). Female Euperipatoides kanangrensis Reid, 1996 were collected from decomposing logs of Eucalyptus trees in Kanangra Boyd National Park, NSW, Australia ( $\left.33^{\circ} 59^{\prime} \mathrm{S} 150^{\circ} 08^{\prime} \mathrm{E}\right)$. Females were kept in containers with dampened sphagnum moss at $13^{\circ} \mathrm{C}$ and were fed crickets once every second week. Gravid females were relaxed and killed with ethyl acetate vapour from October to December in order to acquire embryos of correct stages. Embryos were dissected from the females in phosphate buffered saline (PBS) and, after removal of the egg membranes, fixed in $4 \%$ formaldehyde in PBS overnight at $4^{\circ} \mathrm{C}$. Fixed embryos were dehydrated in a graded series of methanol $(25,50,75 \%$ in PBS with $0.1 \%$ Tween- 20 for 10 minutes each) and stored in $100 \%$ methanol at $-20^{\circ} \mathrm{C}$.

\section{Cloning of six3, otx and tryptophane-2,3-dioxygenase genes}

All primers, PCR programs and template DNA source are given in Additional file 2. Tc-six3 gene was identified by in silico analysis of the Tribolium genome and amplified from a mixed stages ( 0 to $24 \mathrm{~h}$ ) cDNA library. Full length $P d u$-six3 was isolated by screening a $48 \mathrm{~h} \lambda$-ZAP phage library (provided by C. Heimann, Mainz). Pdutryptophane-2,3-dioxygenase gene was identified during a sequencing screen of a $48 \mathrm{~h}$ Platynereis EST library. Gene orthology was confirmed by using NCBI Protein BLAST, MUSCLE [40] multiple sequence alignments and CLUSTALX v.2 neighbour-joining phylogenetic analysis [41] for complete proteins.

\section{Database accession numbers}

Eka-otx: EU347401, Eka-six3: EU347400, Plo-otx: EU330201; Plo-six3: EU330202; Tc-six3: AM922337; Stm-Six3: EU340980; Stm-otx: EU340979; Pdu-six3: FM210809; Pdu-tryptophane-2,3-dioxygenase: FN868644

\section{Whole-mount in situ hybridisation and immunohistochemistry}

Established protocols were used for single- and twocolour fluorescent whole-mount in situ hybridisations of Platynereis and Pristina [42], Euperipatoides [43], Strigamia [44], Drosophila [45], and Tribolium [46]. A Drosophila six3/optix RNA probe was synthesized from EST clone LD05472 (Berkeley Drosophila Genome Project).
Subsequent immunostainings were done using Vector Red (Vector Laboratories, Burlingame, CA, USA) or NBT/BCIP (Roche Diagnostics Penzberg, Germany)). Primary antibodies were: mouse anti-Crumbs (1:50; Developmental Studies Hybridoma Bank, DSHB), mouse antiFas2 (1:20; DSHB), rat anti-Orthodenticle [47] (1:1000, provided by T. Cook), guinea pig anti-Dchx1 antibody (1:1000; provided by T. Erclik), rabbit anti-Six3/Optix antibody (1:300; provided by F. Pignoni), alkaline phosphatase (AP)-coupled sheep anti-digoxygenin (1:1000, Roche). Secondary antibodies: AP-coupled donkey antirat, AP-coupled donkey anti-mouse, Cy5-coupled goat anti-rabbit (Dianova, Hamburg, Germany), Cy3-coupled goat anti-mouse (Dianova, , Hamburg, Germany). SYBRGreen (Invitrogen, San Diego, CA, USA) diluted 1:10.000.

\section{Additional material}

Additional file 1: Supplementary figures and figure legends. Steinmetz_Suppl_Figs.pdf contains two supplementary figures and legends showing multiple sequence alignments of six3 and otx genes, and supporting whole mount in situ hybridisation data of Platynereis, Strigamia, and Euperipatoides larva.

Additional file 2: Supplementary methods. Steinmetz_SupplMethods. $\mathrm{xIs}$ is an Excel Spreadsheet containing primer sequences, template source and PCR programs used to clone six 3 and otx genes presented in the paper.

\section{Abbreviations}

AP: alkaline phosphatase; BCIP: 5-Bromo-4-Chloro-3'Indolyphosphate pToluidine; DSHB: Developmental Studies Hybridoma Bank EST: expressed sequence tags; otd: orthodenticle; NBT: Nitro-Blue Tetrazolium chloride; PBS: phosphate buffered saline; PCR: polymerase chain reaction; PI: pars intercerebralis; PL: Pars lateralis.

\section{Acknowledgements}

We thank Tiffany Cook (Cincinnati Children's Hospital Medical Center) for providing a Drosophila Orthodenticle-antibody. This work was funded by a fellowship from the Luxembourg Ministry of Culture, Higher Education and Research to P.R.H.S., by grants of the Deutsche Forschungsgemeinschaft (DFG) to U.R. (UR 163/1-3, 1-4), by a grant of the Russian Foundation for Basic Research (RFBR) to RPK (09-04-00866-a), through the DFG-Research Center for Molecular Physiology of the Brain and BU-1443/2-2 to G.B, by a BBSRC grant (BBS/B/07519) to C.B and by the Marie Curie RTN ZOONET (MRTN-CT-2004-005624) to M.A. and D.A.

\section{Author details}

'Developmental Biology Unit, European Molecular Biology Laboratory,

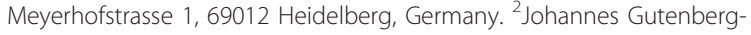
Universität Mainz, Institut für Genetik, J.-J.-Becher-Weg 32, 55128 Mainz,

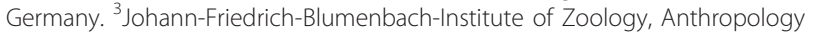
and Developmental Biology, DFG Research Centre for Molecular Physiology of the Brain (CMPB), Georg August University, von-Liebig-Weg-11, 37077 Göttingen, Germany. ${ }^{4}$ University Museum of Zoology, Department of Zoology, Downing Street, Cambridge CB2 3EJ, UK. ${ }^{5}$ Department of Embryology, State University of St. Petersburg, Universitetskaya nab. 7/9, 199034 St. Petersburg, Russia. ${ }^{6}$ University of Vienna, Department for Molecular Evolution and Development, Althanstrasse 14, A-1090 Vienna, Austria. ${ }^{7}$ Vetmeduni Vienna, Institute of Population Genetics, Veterinärplatz 1, A-1210 Vienna, Austria. ${ }^{8}$ Queen Mary University of London, School of Biological and Chemical Sciences, Mile End Road, London E1 4NS, UK. 


\section{Authors' contributions}

PS analysed Platynereis six 3 and otx expression, did multiple sequence alignments, conceived further experiments and wrote the paper. RU performed all Drosophila experiments. JE cloned and analysed Euperipatoides six3 and otx genes. NP performed Tribolium gene expression experiments. RK cloned and analysed six 3 and otx genes in Pristina. CB cloned and analysed Strigamia six3 and otx genes. KG analysed co-expression of Platynereis tryptophane-2,3-dioxygenase and otx genes. MA and GB participated in the design of the study and the writing of the paper. DA designed the study, helped in writing the paper and cloned the Platynereis six3 gene.

\section{Competing interests}

The authors declare that they have no competing interests.

Received: 24 March 2010 Accepted: 29 December 2010

Published: 29 December 2010

\section{References}

1. Siewing R: Lehrbuch der Zoologie. Systematik Stuttgart, New York: Gustav Fischer Verlag; 1985.

2. Orrhage L, Müller MCM: Morphology of the nervous system of Polychaeta (Annelida). Hydrobiologia 2005, 535/536:79-111.

3. Schroeder PC, Hermans CO: Annelida: Polychaeta. In Reproduction of marine invertebrates. Volume 3. Edited by: Giese AC, Pearse JS. New York: Academic Press; 1975:1-213.

4. Ackermann C, Dorresteijn A, Fischer A: Clonal domains in postlarval Platynereis dumerilii (Annelida: Polychaeta). J Morphol 2005, 266:258-280.

5. Jürgens $G$, Hartenstein $V$ : The terminal regions of the body pattern. In The development of Drosophila melanogaster. Volume 1. Edited by: Bate M, Martinez-Arias A. Cold Spring Harbor: CSHL Press; 1993:687-746.

6. Haas MS, Brown SJ, Beeman RW: Pondering the procephalon: the segmental origin of the labrum. Dev Genes Evol 2001, 211:89-95.

7. Rempel JG: The evolution of the insect head: the endless dispute. Quaestiones Entomologicae 1975, 11:7-24.

8. $\quad$ Siewing R: Zum Problem der Arthropodenkopfsegmentierung. Zoologischer Anzeiger 1963, 170:429-468

9. Urbach R, Technau GM: Early steps in building the insect brain: neuroblast formation and segmental patterning in the developing brain of different insect species. Arthropod Structure \& Development 2003, 32:103-123.

10. Schmidt-Ott U, Gonzalez-Gaitan M, Technau GM: Analysis of neural elements in head-mutant Drosophila embryos suggests segmental origin of the optic lobes. Roux Arch dev Biol 1995, 205:31-44.

11. Melnikov OA, Rasnitsyn AP: Zur Metamerie des Arthropoden-Kopfes: Das Acron. Beitr Ent Berlin 1984, 34:3-90.

12. Goodrich ES: On the relation of the arthopod head to the annelid prostomium. Quarterly Journal of Microscopical Science 1897, 40:247-268.

13. Scholtz G, Edgecombe GD: The evolution of arthropod heads: reconciling morphological, developmental and palaeontological evidence. Dev Genes Evol 2006, 216:395-415

14. Tessmar-Raible K, Raible F, Christodoulou F, Guy K, Rembold M, Hausen H, Arendt D: Conserved sensory-neurosecretory cell types in annelid and fish forebrain: insights into hypothalamus evolution. Cell 2007, 129:1389-1400

15. Steinmetz PR, Zelada-Gonzáles F, Burgtorf C, Wittbrodt J, Arendt D: Polychaete trunk neuroectoderm converges and extends by mediolateral cell intercalation. Proc Natl Acad Sci USA 2007, 104:2727-2732.

16. Arendt D, Technau U, Wittbrodt J: Evolution of the bilaterian larval foregut. Nature 2001, 409:81-85

17. Kulakova M, Bakalenko N, Novikova E, Cook CE, Eliseeva E, Steinmetz PR, Kostyuchenko RP, Dondua A, Arendt D, Akam M, Andreeva T: Hox gene expression in larval development of the polychaetes Nereis virens and Platynereis dumerilii (Annelida, Lophotrochozoa). Dev Genes Evol 2007, 217:39-54

18. Oliver G, Mailhos A, Wehr R, Copeland NG, Jenkins NA, Gruss P: six3, a murine homologue of the sine oculis gene, demarcates the most anterior border of the developing neural plate and is expressed during eye development. Development 1995, 121:4045-4055.

19. Carl M, Loosli F, Wittbrodt J: six3 inactivation reveals its essential role for the formation and patterning of the vertebrate eye. Development 2002, 129:4057-4063.
20. Lowe CJ, Wu M, Salic A, Evans L, Lander E, Stange-Thomann N, Gruber CE, Gerhart J, Kirschner M: Anteroposterior patterning in hemichordates and the origins of the chordate nervous system. Cell 2003, 113:853-865.

21. Wei Z, Yaguchi J, Yaguchi S, Angerer RC, Angerer LM: The sea urchin animal pole domain is a six3-dependent neurogenic patterning center. Development 2009, 136:1179-1189.

22. Tomer R, Denes A, Tessmar-Raible K, Arendt D: Profiling by image registration reveals common origin of annelid mushroom bodies and vertebrate pallium. Cell 2010, 142:800-809.

23. Arendt D, Tessmar K, de Campos-Baptista MI, Dorresteijn A, Wittbrodt J: Development of pigment-cup eyes in the polychaete Platynereis dumerilii and evolutionary conservation of larval eyes in Bilateria. Development 2002, 129:1143-1154.

24. Friedrich $\mathrm{M}$ : Ancient mechanisms of visual sense organ development based on comparison of the gene networks controlling larval eye, ocellus, and compound eye specification in Drosophila. Arthropod Structure \& Development 2006, 35:357-378.

25. Van Cleave CD: A study of the process of fission in the naid Pristina longiseta. Physiological Zool 1937, 10:299-314.

26. Bely $A E$, Wray $G A$ : Evolution of regeneration and fission in annelids: insights from engrailed- and orthodenticle-class gene expression. Development 2001, 128:2781-2791.

27. Schröder R: The genes orthodenticle and hunchback substitute for bicoid in the beetle Tribolium. Nature 2003, 422:621-625

28. Posnien N, Bashasab F, Bucher G: The insect upper lip (labrum) is a nonsegmental appendage-like structure. Evol Dev 2009, 11:480-488.

29. Li Y, Brown SJ, Hausdorf B, Tautz D, Denell RE, Finkelstein R: Two orthodenticle-related genes in the short-germ beetle Tribolium castaneum. Dev Genes Evol 1996, 206:35-45.

30. Coiffier D, Charroux B, Kerridge S: Common functions of central and posterior Hox genes for the repression of head in the trunk of Drosophila. Development 2008, 135:291-300.

31. Manton SM: Studies on the Onychophora. VII. The early embryonic stages of Peripatopsis, and some general considerations concerning the morphology and phylogeny of the Arthropoda. Philos Trans R Soc Lond B Biol Sci 1949, 233:483-580.

32. Walker MH, Tait NN: Studies of embryonic development and the reproductive cycle in ovoviviparous Australian Onychophora (Peripatopsidae). Journal of Zoology 2004, 264.

33. Bovolenta P, Mallamaci A, Puelles L, Boncinelli E: Expression pattern of cSix3, a member of the six/sine oculis family of transcription factors. Mechanisms of Development 1998, 70:201-203.

34. Hartenstein $\mathrm{V}$ : The neuroendocrine system of invertebrates: a developmental and evolutionary perspective. J Endocrinol 2006, 190:555-570.

35. de Velasco B, Erclik T, Shy D, Sclafani J, Lipshitz H, Mclnnes R, Hartenstein V: Specification and development of the pars intercerebralis and pars lateralis, neuroendocrine command centers in the Drosophila brain. Dev Biol 2007, 302:309-323.

36. Urbach R, Technau GM: Molecular markers for identified neuroblasts in the developing brain of Drosophila. Development 2003, 130:3621-3637.

37. Simonnet $F$, Célérier $M-L$, Quéinnec E: Orthodenticle and empty spiracles genes are expressed in a segmental pattern in chelicerates. Dev Genes Evol 2006, 216:467-480

38. Browne WE, Schmid BG, Wimmer EA, Martindale MQ: Expression of otd orthologs in the amphipod crustacean, Parhyale hawaiensis. Dev Genes Evol 2006, 216:581-595

39. Bruce $A E$, Shankland M: Expression of the head gene Lox22-Otx in the leech Helobdella and the origin of the bilaterian body plan. Dev Biol 1998, 201:101-112

40. Edgar RC: MUSCLE: multiple sequence alignment with high accuracy and high throughput. Nucleic Acids Res 2004, 32:1792-1797.

41. Larkin MA, Blackshields G, Brown NP, Chenna R, McGettigan PA McWilliam H, Valentin F, Wallace IM, Wilm A, Lopez R, Thompson JD, Gibson TJ, Higgins DG: Clustal W and Clustal $\times$ version 2.0. Bioinformatics 2007, 23:2947-2948.

42. Tessmar-Raible K, Steinmetz PRH, Snyman H, Hassel M, Arendt D: Fluorescent two color whole-mount in situ hybridization in Platynereis dumerilii (Polychaeta, Annelida), an emerging marine molecular model for evolution and development. BioTechniques 2005, 39:460, 462, 464 
43. Eriksson B, Tait N, Budd GE, Akam M: The involvement of engrailed and wingless during segmentation in the onychophoran Euperipatoides kanangrensis (Peripatopsidae: Onychophora) (Reid 1996). Dev Genes Evol 2009, 219:249-264.

44. Chipman AD, Arthur W, Akam M: Early development and segment formation in the centipede, Strigamia maritima (Geophilomorpha). Evol Dev 2004, 6:78-89.

45. Plickert G, Gajewski M, Gehrke G, Gausepohl H, Schlossherr J, Ibrahim H: Automated in situ detection (AISD) of biomolecules. Dev Genes Evol 1997, 207:362-367.

46. Wohlfrom H, Schinko JB, Klingler M, Bucher G: Maintenance of segment and appendage primordia by the Tribolium gene knodel. Mech Dev 2006, 123:430-439.

47. Xie B, Charlton-Perkins M, McDonald E, Gebelein B, Cook T: senseless functions as a molecular switch for color photoreceptor differentiation in Drosophila. Development 2007, 134:4243-4253.

48. Urbach R: A procephalic territory in Drosophila exhibiting similarities and dissimilarities compared to the vertebrate midbrain/hindbrain boundary region. Neural Dev 2007, 2:23.

49. Telford MJ: Evidence for the derivation of the Drosophila fushi tarazu gene from a Hox gene orthologous to lophotrochozoan Lox5. Curr Biol 2000, 10:349-352.

50. Telford MJ, Thomas RH: Expression of homeobox genes shows chelicerate arthropods retain their deutocerebral segment. Proc Natl Acad Sci USA 1998, 95:10671-10675.

51. Hughes $\mathrm{CL}$, Kaufman TC: Hox genes and the evolution of the arthropod body plan. Evol Dev 2002, 4:459-499.

52. Hirth F, Kammermeier L, Frei E, Walldorf U, Noll M, Reichert H: An urbilaterian origin of the tripartite brain: developmental genetic insights from Drosophila. Development 2003, 130:2365-2373.

53. Damen WG, Hausdorf M, Seyfarth EA, Tautz D: A conserved mode of head segmentation in arthropods revealed by the expression pattern of Hox genes in a spider. Proc Natl Acad Sci USA 1998, 95:10665-10670.

doi:10.1186/2041-9139-1-14

Cite this article as: Steinmetz et al: Six3 demarcates the anterior-most developing brain region in bilaterian animals. EvoDevo 2010 1:14.

\section{Submit your next manuscript to BioMed Central and take full advantage of:}

- Convenient online submission

- Thorough peer review

- No space constraints or color figure charges

- Immediate publication on acceptance

- Inclusion in PubMed, CAS, Scopus and Google Scholar

- Research which is freely available for redistribution

Submit your manuscript at www.biomedcentral.com/submit
Biomed Central 